\title{
On the disclosure of ticket sales in charitable lotteries
}

Citation for published version (APA):

Damianov, D. S., \& Peeters, R. (2016). On the disclosure of ticket sales in charitable lotteries. Maastricht University, Graduate School of Business and Economics. GSBE Research Memoranda No. 030 https://doi.org/10.26481/umagsb.2016030

Document status and date:

Published: 01/01/2016

DOI:

10.26481/umagsb.2016030

\section{Please check the document version of this publication:}

- A submitted manuscript is the version of the article upon submission and before peer-review. There can be important differences between the submitted version and the official published version of record.

People interested in the research are advised to contact the author for the final version of the publication, or visit the DOI to the publisher's website.

- The final author version and the galley proof are versions of the publication after peer review.

- The final published version features the final layout of the paper including the volume, issue and page numbers.

Link to publication

\footnotetext{
General rights rights.

- You may freely distribute the URL identifying the publication in the public portal. please follow below link for the End User Agreement:

www.umlib.nl/taverne-license

Take down policy

If you believe that this document breaches copyright please contact us at:

repository@maastrichtuniversity.nl

providing details and we will investigate your claim.
}

Copyright and moral rights for the publications made accessible in the public portal are retained by the authors and/or other copyright owners and it is a condition of accessing publications that users recognise and abide by the legal requirements associated with these

- Users may download and print one copy of any publication from the public portal for the purpose of private study or research.

- You may not further distribute the material or use it for any profit-making activity or commercial gain

If the publication is distributed under the terms of Article $25 \mathrm{fa}$ of the Dutch Copyright Act, indicated by the "Taverne" license above, 


\section{Maastricht University}

Damian S. Damianov,

Ronald Peeters

On the disclosure of ticket sales in charitable lotteries

$\mathrm{RM} / 16 / 030$

\section{GSBE}

Maastricht University School of Business and Economics

Graduate School of Business and Economics

P.O Box 616

NL- 6200 MD Maastricht

The Netherlands 


\title{
On the disclosure of ticket sales in charitable lotteries
}

\author{
Damian S. Damianov* Ronald Peeters ${ }^{\dagger}$
}

September 21, 2016

\begin{abstract}
We show that a policy of disclosing the ticket sales during a fundraising lottery raises total revenue when there are more than two bettors. The optimal timing of the disclosure is when about half of the players have purchased lottery tickets.
\end{abstract}

JEL classification codes: D44, D62, D64.

Keywords: Charity lotteries, Ticket sales, Disclosure policy.

\section{Introduction}

Charitable lotteries constitute a significant source of funding for the provision of public goods and services both at a national and a local level. Proceeds from lottery ticket sales are used to fund health, education and environmental protection initiatives as well as sports, arts, and national heritage programs. According to the North American Association of State and Provincial Lotteries, in 2014 lottery ticket sales in the United States exceeded $\$ 70$ billion. That is, in 2014 Americans spent more on lottery tickets than on sports events, books, video games, movies, and music combined (see Isidore 2015; Thompson 2015). Given the high revenues generated by lottery ticket sales, even small changes in the way lotteries are organized and operated can have a substantial impact on funding for charitable causes.

The effectiveness of lotteries as a means of raising funds for public goods was discussed by Morgan (2000) who showed that a lottery generates more funds than a voluntary contribution scheme. The recent literature has examined various ways to further enhance revenues in fundraising lotteries whereby most efforts have been focused on the use of alternative ticket pricing schemes. In a two-player framework, Franke and Leininger (2014) show that, when donors are budget constrained and heterogeneous, it is optimal to bias the lottery in favour of a specific player, and such a biased lottery design is able to generate the efficient amount of

\footnotetext{
${ }^{*}$ Durham University Business School, Mill Hill Lane, Durham DH1 3LB, UK. Tel: ++44 (0) 1913345528. Fax: ++44 (0) 19133 45201. E-mail: damian.damianov@durham.ac.uk.

${ }^{\dagger}$ Department of Economics, Maastricht University, PO Box 616, 6200 MD Maastricht, The Netherlands. Tel: ++31 (43) 3883730. Fax: ++31 (43) 3884878. E-mail: r.peeters@maastrichtuniversity.nl.
} 
public good provision. Damianov (2015) demonstrates that discounts on lottery tickets raise total revenue when players are sufficiently heterogeneous in the way they value the prize.

In this paper we explore an alternative, easily implementable way of enhancing revenues in fundraising lotteries. We study the impact of disclosing the number of lottery tickets purchased at a given stage of the fundraising event on subsequent sales, on initial sales, and ultimately on total revenue. We show that such a disclosure policy increases total revenue in lotteries with more than two bettors whereby the highest amount of funds is raised when the disclosure occurs once half of the bettors have bought tickets.

\section{The baseline model}

We consider a lottery with $N \geq 2$ players who arrive at a fundraising event and decide on the number lottery tickets to purchase. The value of the lottery prize is denoted by $v$ and the revenue generated by ticket sales is used to finance a public good. The per capita return from the public good is denoted by $\alpha$, whereby $0 \leq \alpha<1$. In the baseline model without disclosure of ticket sales, the expected payoff of bettor $i$ is given by

$$
u\left(x_{i}, x_{-i}\right)=\frac{x_{i}}{x_{i}+\sum_{j \neq i} x_{j}} \cdot v-x_{i}+\alpha \cdot\left(x_{i}+\sum_{j \neq i} x_{j}\right),
$$

where $x_{i} \geq 0$ is the amount spent on lottery tickets by bettor $i=1,2, \ldots, N$ and $x_{-i}$ is the vector of amounts spent by the other players. ${ }^{1}$ It is easy to demonstrate that the so defined lottery game is isomorphic (i.e. has the same equilibria) to a game without a public good component but with an adjusted prize of $V=\frac{v}{1-\alpha}$. Without loss of generality we can normalize the value of the adjusted prize to unity $(V=1)$ and obtain the following alternative representation for the expected payoff of player $i$

$$
U\left(x_{i}, x_{-i}\right)=\frac{x_{i}}{x_{i}+\sum_{j \neq i} x_{j}}-x_{i} .
$$

In the baseline model of no disclosure of ticket sales bettors move simultaneously. The considered game is thus equivalent to a classical Tullock contest. It is well known that in Nash equilibrium each bettor spends the amount

$$
x_{i}^{*}=\frac{N-1}{N^{2}}
$$

and total revenue equals

$$
Y^{*}=\frac{N-1}{N}
$$

\footnotetext{
${ }^{1}$ In the case in which no player buys lottery tickets, i.e. $x_{i}+\sum_{j \neq i} x_{j}=0$, we assume that the prize is not awarded and the expected payoff of each player is zero.
} 


\section{Disclosure of ticket sales}

We assume now that the number of tickets sold is disclosed once the first $n$ players who arrive have bought lottery tickets. After this information is revealed, the remaining $k=N-n$ players also purchase lottery tickets upon their arrival. That is, the disclosure policy creates a sequential structure, and we explore here the behavior of the first movers and the second movers in a symmetric subgame perfect Nash equilibrium.

In the following analysis we first establish a relationship between ticket purchases of players in the second stage of the game, $y$ and total revenue $Y$ in a symmetric subgame perfect equilibrium (Lemma 1). Then we derive relationships between ticket purchases in the first stage of the game $x$ and total revenue $Y$ in equilibrium (Lemma 2). These steps allow us to derive our main result, which establishes how equilibrium revenue $Y$ in the lottery depends upon the number of first movers $n$ and the number of second movers $k$ in the game (Proposition 1). We show that the lottery revenue when $n$ players move first and $k$ players move second is equal to the revenue when $k$ players move first and $n$ players move second (Corollary 1). We further demonstrate that the policy of disclosing ticket sales raises more revenue compared to a non-disclosure policy when there are three or more bettors (Corollary 2). That is, the well-known revenue equivalence between the Stackelberg and Cournot rent-seeking game with two bettors (see, e.g. Dixit 1987; Linster 1993) breaks down once the number of players is increased. Finally, we prove that the maximum revenue is obtained when about half of the players buy lottery tickets before ticket sales are disclosed (Corollary 3).

Let all the first movers spend the amount $x \geq 0$ and all the second movers, except for player $j$, spend the amount $y \geq 0$. Player $j$ chooses $y_{j}$ so as to maximize

$$
\frac{y_{j}}{n x+(k-1) y+y_{j}}-y_{j}
$$

The first order condition is given by

$$
\frac{n x+(k-1) y}{\left(n x+(k-1) y+y_{j}\right)^{2}}=1 .
$$

In a symmetric equilibrium we require that $y_{j}=y$, and as a response to the first movers playing $x$ in the first stage, using equation (1) we obtain that the second movers play $y(x)$ implicitly given by the equation

$$
n x+(k-1) y=(n x+k y)^{2} .
$$

Total revenue in the lottery corresponds to the sum of tickets sold in the first stage and tickets sold in the second stage and is given by $Y=n x+k y$. With these preliminaries we establish our first result. 
Lemma 1 (Second movers). In a symmetric subgame perfect equilibrium, tickets purchased by a player in the second stage of the game $y$ and total revenue $Y$ satisfy the following relationship

$$
y=Y-Y^{2} .
$$

Proof. As total revenue is $Y=n x+k y$ from equation (2) we obtain $Y-y=Y^{2}$.

We now rearrange equation (2) and define

$$
\varphi(x, y):=n x+(k-1) y-(n x+k y)^{2} \equiv 0 .
$$

Next, we calculate the derivative $y^{\prime}(x)$ as the ratio

$$
y^{\prime}(x)=-\frac{\partial \varphi(x, y)}{\partial x} / \frac{\partial \varphi(x, y)}{\partial y}=\frac{n[2(n x+k y)-1)]}{k[1-2(n x+k y)]-1}=\frac{n(2 Y-1)}{k-2 k Y-1} .
$$

The reaction of a follower resulting from a change in the strategy of one of the first movers at the point $x_{i}=x$ while the other first movers play $x$ is hence given by

$$
y^{\prime}\left(x_{i}\right)=\frac{y^{\prime}(x)}{n}=\frac{2 Y-1}{k-2 k Y-1} .
$$

We can now move to the analysis of the first stage of the game. The payoff of player $i$ in a subgame perfect equilibrium when all other first movers play $x$ and all the second movers react with $y\left(x_{i}\right)$ is given by

$$
\frac{x_{i}}{x_{i}+(n-1) x+k y\left(x_{i}\right)}-x_{i} .
$$

For the first order condition we obtain

$$
\frac{(n-1) x+k y\left(x_{i}\right)-x_{i} k y^{\prime}\left(x_{i}\right)}{\left[x_{i}+(n-1) x+k y\left(x_{i}\right)\right]^{2}}=1 .
$$

With these preliminaries we establish our second result.

Lemma 2 (First movers). In a symmetric subgame perfect equilibrium, the tickets purchased by a player in the first stage of the game $x$ and the total revenue $Y$ satisfy the following relationships

$$
\frac{Y-x-k x \cdot \frac{2 Y-1}{k-2 k Y-1}}{Y^{2}}=1
$$

and

$$
x=\frac{Y(k Y-k+1)}{n} .
$$

Proof. In a symmetric equilibrium we have $x_{i}=x$, and substituting the expression for $y^{\prime}\left(x_{i}\right)$ derived in equation (3) into equation (4) we obtain the result stated in equation (5). The result in equation (6) follows from the definition $Y=n x+k y$ and the relationship $y=Y-Y^{2}$ established in Lemma 1.

These preliminaries allow us to determine how total revenue depends on the number of leaders and followers. 
Proposition 1 (Main result). In a symmetric subgame perfect equilibrium, total revenue is given by

$$
Y=\frac{3 n k-N+\sqrt{(n k+N)^{2}-8 n k}}{4 n k} .
$$

The proof is provided in the appendix. This result allows us to establish the following properties of the ticket disclosure policy.

Corollary 1 (Symmetry). A disclosure policy according to which $n$ players move first and $k$ players move second generates the same revenue as a disclosure policy in which $k$ players move first and $n$ players move second.

Proof. The corollary follows straightforwardly from the property that total revenue depends on the product $n k$.

Corollary 2 (Disclosure vs non-disclosure). The policy of ticket sales disclosure raises more revenue than the non-disclosure policy for any $N \geq 3$.

Proof. From Lemma 3 in the appendix it follows that the lowest revenue under a disclosure policy is obtained in the scenario with only one first mover or only one second mover, i.e. when $n k$ is minimal and equal to $N-1$. For $n k=N-1$ direct substitution in equation (7) shows that the revenue equals $\frac{2(N-1)-1}{2(N-1)}$ which exceeds the revenue of $\frac{N-1}{N}$ under the non-disclosure policy.

Corollary 3 (Maximum revenue). Total revenue monotonically increases in $n$ for $n<\frac{N}{2}$, reaches a maximum for $n=\frac{N}{2}$ and monotonically decreases in $n$ for $n>\frac{N}{2}$.

Proof. From Lemma 3 in the appendix we know that the lottery revenue increases in $n k$, hence revenue is maximized when $n k=n(N-n)$ reaches its maximum. That is, the revenue increases for $n<\frac{N}{2}$, reaches a maximum at $n=\frac{N}{2}$ and decreases for $n>\frac{N}{2}$.

\section{Conclusion}

In this paper we contribute to two strands of literature: the literature on sequential fundraising and the literature on precommitment in contests. In a complete information voluntary contribution public good game, Varian (1994) shows that the disclosure of donations can be suboptimal as it allows the first mover to free ride leaving the burden of financing the public good to the second mover. Vesterlund (2003), in contrast, constructs a model to demonstrate that under imperfect information the often used strategy of announcing past donations by fundraisers have an informational value and, under certain conditions, increases total revenue. Given that lotteries are widely used for fundraising and have the potential to generate more funds than voluntary contributions (Morgan 2000), the question of whether the announcement of ticket sales has an impact on revenue is relevant both from a practical and a 
theoretical standpoint. In this paper we study the effect of such a disclosure policy on revenue in the context of a fundraising lottery and show that this policy increases contributions even in a complete information framework. The paper also generalizes and extends the results in the literature on precommitment in contests derived by Dixit (1987) and Glazer and Hassin (2000) by providing a closed form solution to the Tullock sequential rent seeking contest with multiple leaders and multiple followers.

\section{Appendix: Proofs}

Proof of Proposition 1. Solving the system of equations (5) and (6) presented in Lemma 2, we obtain that $Y$ satisfies the quadratic equation

$$
2 n k \cdot Y^{2}-(3 n k-N) \cdot Y+(n k-N+1)=0 .
$$

For ease of exposition we denote the left hand-side of equation (8) by $f(Y)$ and the product of the number of first movers and the number of second movers by $z=n k>0$. The solutions to equation (8) are given as follows

$$
\begin{aligned}
Y_{1} & =\frac{3 z-N+\sqrt{(z+N)^{2}-8 z}}{4 z} \\
Y_{2} & =\frac{3 z-N-\sqrt{(z+N)^{2}-8 z}}{4 z} .
\end{aligned}
$$

For the discriminant we obtain

$$
(z+N)^{2}-8 z \geq N^{2}-2 z+z^{2}>(1-z)^{2} \geq 0
$$

and hence the two solutions are real numbers. We now proceed by contradiction to show that $Y_{2}$ does not constitute an equilibrium. For the case of either only one first mover $(n=1)$ or only one second mover $(k=1)$, we have $z=N-1$. For this value of $z$ we obtain $Y_{2}=0$. This means no player buys a lottery ticket, which cannot be an equilibrium as a player who moves second would have a profitable deviation. For the case of two or more first movers $(n>1)$ and two or more second movers $(k>1)$ we will show that, for the solution $Y_{2}$, first movers purchase a negative amount of tickets: $x<0$. Observe that $f(Y)>0$ at $Y=0$ and $Y=1$, $f^{\prime}(Y)<0$ at $Y=0$ and $f^{\prime}(Y)>0$ at $Y=1$. Hence, the following inequalities hold

$$
0<Y_{2}<Y_{1}<1
$$

From $0<Y_{2}$ and equation (6) follows that the sign of $x$ is determined by the expression $k Y-k+1$. This expression is negative if and only if

$$
k \cdot \frac{3 n k-N-\sqrt{(n k+N)^{2}-8 n k}}{4 n k}-k+1<0
$$


or, equivalently,

$$
\sqrt{(n k+N)^{2}-8 n k}>4 n-(n k+N) .
$$

If $4 n-(N+n k)<0$, the inequality holds. If $4 n-(N+n k) \geq 0$, the inequality is equivalent to

$$
(n k+N)^{2}-8 n k>(4 n-(n k+N))^{2} \Longleftrightarrow n(k-1)>0,
$$

which holds for $k>1$.

Next, we show that both first and second movers purchase a positive amount of tickets for the solution $Y_{1}$, i.e. $y>0$ and $x>0$, so that $Y_{1}$ is indeed an equilibrium. The condition $y>0$ follows from Lemma (1) and the inequality $0<Y_{1}<1$ presented in (9). We turn now to verifying that $x>0$. Note first that for $k=1$, the inequality $x>0$ follows from $Y_{1}>0$. For the case of two or more second movers, i.e. $k>1$, the quantity $x$ is positive if and only if

$$
k \cdot \frac{3 n k-N+\sqrt{(n k+N)^{2}-8 n k}}{4 n k}-k+1>0
$$

or, equivalently,

$$
\sqrt{(n k+N)^{2}-8 n k}>(n k+N)-4 n .
$$

If $4 n-(n k+N)<0$, the inequality is satisfied. If $4 n-(n k+N) \geq 0$, the inequality is equivalent to

$$
(n k+N)^{2}-8 n k>((n k+N)-4 n)^{2} \Longleftrightarrow n(k-1)>0,
$$

which is satisfied for $k>1$.

Lemma 3 (Monotonicity). The equilibrium revenue

$$
Y(z)=\frac{3 z-N+\sqrt{(z+N)^{2}-8 z}}{4 z}
$$

is increasing in $z$.

Proof. We represent the equilibrium revenue as follows

$$
Y(z)=\frac{1}{4}\left(3-\frac{N}{z}+\sqrt{1+\frac{2 N}{z}-\frac{8}{z}+\frac{N^{2}}{z^{2}}}\right) .
$$

Taking the derivative $Y^{\prime}(z)$ and simplifying we obtain that $Y^{\prime}(z)>0$ if and only if

$$
N \sqrt{z^{2}+2 N z-8 z+N^{2}}>N z-4 z+N^{2} .
$$

This inequality is satisfied if the right hand-side is negative. Otherwise, the inequality is equivalent to

$$
N^{2}\left(z^{2}+2 N z-8 z+N^{2}\right)>\left(N z-4 z+N^{2}\right)^{2} .
$$

It is easy to see that it is satisfied for all $N>2$. Note that in the case $N=2$ the only alternative for a sequential lottery is $n=k=1$ and $z=1$. 


\section{References}

Damianov, D.S. (2015). "Should lotteries offer discounts on multiple tickets," Economics Letters, 126, pp. 84-86.

Dixit, A. (1987). "Strategic behavior in contests," American Economic Review, 77(5), pp. 891-898.

Franke, J., Leininger, W. (2014). "On the efficient provision of public goods by means of biased lotteries: the two player case," Economic Letters, 125, pp. 436-439.

Glaser, A., Hassin, R. (2000). "Sequential rent seeking," Public Choice, 102, pp. 219-228.

Isidore, C. (2015). "Americans spend more on the lottery than on ...", CNNMoney (New York), February 11, 2015.

Linster, B.G. (1993). "Stackelberg rent-seeking," Public Choice, 77(2), pp. 307-321.

Morgan, J. (2000). "Financing public goods by means of lotteries," Review of Economic Studies, 67, pp. 761-784.

Thompson, D. (2015). "Lotteries: America's $\$ 70$ billion shame," The Atlantic, May 11, 2015.

Varian, H.R. (1994). "Sequential provision of public goods," Journal of Public Economics, 53, pp. $165-186$.

Vesterlund, L. (2003). "The informational value of sequential fundraising," Journal of Public Economics, 87, pp. 627-657. 